\title{
Towards a Spiritual Pedagogy of Pastoral Welfare and Care
}

This paper considers the role of spirituality in the practice of pastoral welfare and care in English state schools. Set against an educational landscape of increasingly aggressive neoliberal interests combined with growing public disquiet over the metal welfare of young people, the author examines how spirituality might in response contribute to a pedagogy of pastoral welfare for pupil wellbeing. The paper begins by foregrounding the policy contexts for pastoral education in England and the challenges presented by the increasingly performative cultures that schools, children and young people have become subjected to. Highlighting concerns around the well-being of children and young people, the paper advances a spiritual pedagogy in pastoral care predicated on pivotal interrelated attributes of intrapersonal transcendence, care and educational practice. The paper then considers the possibilities presented by the spiritual realm in pastoral welfare and the positioning of this as an educational pedagogy and practice.

Key words: spirituality, pedagogy, care, transcendence, practice

\section{$\underline{\text { Introduction }}$}

In recent years the well-being of children and young people has been a topic of increasing concern both within the UK and in other international contexts. Reflected in recent reports by the Children's Society (Layard and Dunn, 2009), the National Institute for Care Excellence (2013), the Office for National Statistics (ONS; 2014), the Organisation for Economic Co-Operation and Development (OECD; 2015) and UNICEF (2007), the well-being of children and young people has become an emerging issue of national policy concern. While definitions of child well-being are variously defined in the literature, common characteristics typically coalesce around the domains of physical, psychological, cognitive, social and economic well-being (Pollard and Lee, 2003). UNICEF, in its influential survey of child well-being (2007) discuss six dimensions of well-being: material wellbeing, health and safety, educational well-being, family and peer relationships, behaviours and risks, and subjective well-being. On the basis of these dimensions UNICEF conclude that the UK, alongside the USA, has the worst profile of child well-being amongst the world's twenty-one richest countries. While some reportage has given justifiable attention to the economic factors governing child wellbeing, bodies such as NICE have devoted their attention to the domains of emotional wellbeing (being happy, confident and not unduly anxious or depressed); psychological wellbeing (involving personal autonomy, problem-solving and resilience, managing emotions and exercising empathy) and social wellbeing (developing positive relationships with others and not exhibiting disruptive, 
violent or a bullying behaviour) (NICE, 2013). With explanations of wellbeing relying predominantly on models of cognitive and interpersonal psychology, less attention has been given to the spiritual development of young people as part of a broadly-based project of improving well-being. The identification of spiritual education in the English school system does, however, have a long but nonetheless poorly-defined history. While much of the interest in addressing the spiritual realm of young people as a matter of educational concern can be traced to the inclusion of spiritual, moral, social and cultural (SMSC) education in the curriculum aims of the Education Reform Act of 1988 (and the requirement for this to be reported on as part of school inspection), precise and coherent definitions of the field have remained elusive (Brown, 1996). In the UK, the emergence of learned societies and scholarship devoted to the field, e.g. the International Journal of Children's Spirituality of the Association of Children's Spirituality have provided one example of an attempt to develop more meaningful lines of discussion. Despite much of the scholarship around spirituality in the UK focusing on faith and religious practices, studies of the field in North America have typically drawn on cognitive psychology in an attempt to offer both explanation and measurement of the spiritual realm by means of demonstrating such things as cognitive and phenomenological orientation, existential well-being, paranormal beliefs and religious dispositions (MacDonald, 2000; Hill and Pargament, 2008). Elsewhere, work by Heron (1998) in the realm of person-centred enquiry has focused on revealing the essence of spiritual encounters through co-participatory encounters. Meanwhile, the continuing tensions around spirituality in educational contexts have been further highlighted by Best (2008), Bigger (2008) and Marples (2006) in their response to the challenges around the possibilities of the spiritual realm as an educational concern. Notwithstanding the continuance of contested standpoints around spiritual experience, the emergence of well-being as a policy concern coupled with professional disquiet around increasingly corrosive forms of performativity in the province of education and care has given renewed impetus to the possibilities offered by the spiritual domain.

\section{A brief policy context of Education in the UK}

Over the past thirty years public education in England has undergone an unprecedented level of state intervention. In the wake of the 1988 Education Reform Act concerns amongst the teaching profession about the effects of an emerging evaluation culture (Campbell and Husbands, 2000) have since given way to greater alarm over the detrimental effects of performativity within a larger political project of neoliberalisation (Ball, 2003; Jeffrey and Troman, 2012). Lyotard (1984) describes performativity as both a culture and technology, involving the macro-societal pursuit of efficiency and outcomes governed by narrow bureaucratic forms of output and accountability. Performativity 
has subsequently become the defining feature of public service remodernisation in England, and from which Education has not been immune. As the intensification of data-evidencing in schools bears testimony to, pivotal to performative cultures is the assumption that it is possible to precisely gauge and make transparent the performance of the core activities of an organisation (Lyotard, 1984). Moreover, as Wayne Ross and Gibson note (2006), in dominant neo-liberal cultures where market freedom, privatisation and competition are valorised, such assumptions are asserted to have no credible alternative. In England the embracing of neo-liberal interests by successive governments has seen in state education an increasingly intrusive regulation of the curriculum, punitive forms of accountability through the Office for Standard in Education (Ofsted) and the forced academisation by government of those schools deemed to have failed centrally determined standards. While terms such as 'special measures' are now part of the educational lexicon and a failing school is assured media interest, less has been known about the effects of performative cultures on children and young people. Amongst the early exceptions, Cullingford $(1999,6)$ has reported the anxieties felt by primary age children during school inspection. Park (2013) has noted the debilitating effects of Ofsted on children and young people as they are made to feel responsible for judgements about their school on the basis of their test performance. Burke and Grosvenor $(2003,70)$ also describe young people's criticism of testing in schools and its increasing separation from meaningful learning while Author et al (ref) have reported the concerns of adolescent pupils being pressured into making early and potentially detrimental examination choices. In a comprehensive assessment of the impacts of performativity on pupil well-being, Hutchings (2015) report for the National Union of Teachers highlights the anxieties and stress now being induced amongst young people as part of the pressure to perform in English state schools. Combined with the World Health Organisation's (2012) finding that 11-16 year-old pupils in England feel more pressured by their school work than in the majority of other European countries, and evidence from the Children's Charity Childline $(2014,2015)$ of a 200 percent increase in counselling sessions related to exam stress in the period 2012-2014, the effects of performative cultures have become increasingly visible. While author (ref) has noted that key transition points in statutory education also coincide with times of significant physical and emotional change for young people, Mayall's (2007) research for the Cambridge Primary Review reports that the home has become increasingly regarded as an extension of school, with homework encroaching significantly on the time for children to enjoy non-school activities. Hence, it perhaps unsurprising that concerns over pupil wellbeing are now the subject of increasing political as well as professional and attention.

\section{Wellbeing: whose concern?}


As noted in the introduction to this paper, the well-being of children and young people has now become a matter of transnational policy interest derived from often differing configurations of assessment and emphasis of approach. The emergence of well-being as an educational issue also owes something to earlier preoccupations with themes of emotional literacy and emotional intelligence largely popularised in the writings of Daniel Goleman (1996). While this has served to highlight the importance of the relationship between cognition and affect in lifeworlds of young people, in some quarters it has contributed to what Ecclestone and Hayes $(2009,137)$ have described as a diminution of the human self as a consequence of well-intentioned but nonetheless misguided preoccupations with forms of therapeutic education. Amongst the underlying problems that inform Ecclestone and Hayes concerns is the prevalence of adult anxieties over the behaviour of young people with little or no attempt to engage their viewpoints. In their study of young people and risk Author (ref) report the disparity between the moral panics typically governing adult perspectives of young people (such as stranger danger and cyber criminality) and the legitimate worries of young people related to often less visible forms of risk in school settings, such as interpersonal relationships, identity, lifestyle and restricted career choices caused be enforced early examination options. In contrast, in undertaking its 'Good Childhood Report' (2015) The Children's Society set out with a clear and alternative mandate to understand the wellbeing of children and young people, noting that the debate about their well-being was not adequately representing their views and experiences both in the UK and internationally. The report states that:

'Children's well-being was being discussed primarily in relation to adult concerns, which focused on negative behaviours (eg drinking and drug use) and on their future well-being - or 'well-becoming' - as productive members of society (eg educational attainment).'

(The Children's Society, 2015, 11)

Furthermore, the report's authors go on to highlight that while increasing attention is now being given to subjective, as well as the measurement of objective, well-being amongst adult populations, the subjective well-being of young people is notably absent in the discussion $(2015,9)$. Hence, the ramifications for pastoral education and the possibilities for spiritual education are significant.

\section{Pastoral Welfare and the possibility of the spiritual}

In reviewing the conditions of pastoral education in UK schools at the turn of the millennium, Best helpfully reminds us that pastoral welfare is a uniquely British concept (Best, 2000a, 3). While practitioners and academics have struggled to meaningfully define its epistemic field, they have also had to resolve criticisms over its problematic historical roots in religious hierarchy and paternalism (Best 2000a, 4). Meanwhile, pastoral welfare as curriculum concern has tended to coalesce around 
imperatives of care, personal and social development and civic responsibility. The inclusion of the spiritual development as part of what was to become a government strategy for the promotion of spiritual, moral, social and cultural (SMSC) education in the curriculum in the mid1990s, has, in turn, added more complexity to problems of definition. Writing specifically on this issue Best (2000b) notes the longstanding controversies around attempts to disaggregate and evaluate holistic areas of school experience. In particular, Best notes that the spiritual dimension has been the least amenable to definition. Referring readers to the School Curriculum Assessment Authority (SCAA) 1996 conference on SMSC, Best notes those aspects that made the shortlist for spiritual development: religion, thinking, prayer, meditation, ritual, the awakening of feelings of awe and wonder in nature and the universe, positive relations with others and essentially reflection and learning from one's experiences (SCAA, 1996, 6-7 in Best, 2000b, 10). Despite the challenges of definition, the attractiveness of a spiritual dimension in education continues to sustain in the discourses of education while remaining largely unfulfilled as both a curriculum and pedagogic project.

The promotion of the spiritual welfare in the field of healthcare has, in contrast, enjoyed a long history of development with much of the discourse focusing on the concept of spiritual transcendence. Sulmasy (1999) typifies the dominant lines of argument, noting that while both spirituality and medicine have a long history, 'for much of that history the rupture between medicine and spirituality that characterizes Western medicine at the brink of the 21st century is a distinct anomaly'. Sulmasy argues that spirituality is primarily defined by our relationship with the transcendent and that this can be experienced in and through the practice of medicine as one that 'involves personal relationships with patients and always raises transcendent questions for patients and practitioners' (p.1002). Sulmasy's definition of the spiritual as the individual's relationship with the transcendent is a common and recurrent theme in accounts of the phenomenon. Hunt and West (2007) similarly report a strong reciprocity between personal perspectives of the spiritual and the 'transcendental' or 'transpersonal', noting that:

the former acknowledges the mysterious, an 'outside' of the known and knowable universe which nevertheless penetrates and animates that universe; the latter does not admit the possibility of anything beyond the known and knowable but operates at a subtle level of inter-subjective experience.

Developing earlier lines of enquiry methods established by Heron (1998), Hunt and West's research points to the 'nourshing' and/or 'inspiring' spaces of transcendent participation and how these contrast with the participants' usual working environments. Coyle (2002) in her study of spirituality in healthcare points to a trichotomy of approaches. In the first of these, the transcendent approach, transcendence is seen as an essential quality of spirituality. In the second, spirituality is regarded as 
residing in the province of the personal values that gives life meaning and purpose - a value guidance approach. In her third approach, Coyle describes a structural-behaviourist view, where the focus is on those 'reproduced actions' and behaviours associated with organized religion (Coyle, 2002, 592). While, in the first of this trichotomy, Coyle points to transcendence as an essential feature of spirituality, she makes the important distinction between transpersonal and intrapersonal transcendence. Transcendence of a transpersonal kind involves experiences of connection to a higher power, consciousness and God - experiences typically reported by members of communities of faith - while intrapersonal transcendence concerns inner knowing, inner resource and the potentiality of the self (Coyle, 2002, 590). Coyle asserts that this latter orientation to transcendence in the spiritual realm is one that has been widely reconstructed within the social sciences. Mirroring Socratic ideas of inner knowing combined with inner resource and the potentiality of self provides important correspondences with the affective labour of teaching as a spiritual endeavour. Moreover, as Hickson and Phelps (1997) observe, the spiritual person can be regarded as one who has a strong sense of social justice with a commitment to altruistic love and action. It is this orientation to intrapersonal transcendence that has much to offer in the province of a spiritual orientation to pastoral welfare for the wellbeing of young people in educational settings. Following Sulmasy's assertion that the spiritual needs of patients are necessarily enhanced by clinicians intensifying a commitment to their own spiritual beliefs and practices (Sulmasy, 1999, 102), this casts important light on how a pedagogy of spiritual practice might be achieved in pastoral education in an English context of performativity and heightened concern for the well-being of children and young people.

\section{Towards a spiritual pedagogy}

In addition to advancing a specific orientation to spirituality in the context of education policy already described - intrapersonal transcendence against perfomative cultures - scholarship around the term pedagogy offers important insights into how this might be usefully configured with a spirituality of intrapersonal transcendence. In the UK, Brian Simon in his seminal paper 'Why No Pedagogy in England?' (1981) famously lamented the absence of pedagogy in English educational practice while noting its 'honoured place' in continental Europe. From the Greek paidagoggia 'to lead or tend to the child ' the development pedagogy in continental Europe can be traced to the writings of Comenius in the Seventeen century and in the later work of Herbart. In turn, pedagogy was to become broadly defined, embracing areas as diverse as health and bodily fitness, social and moral welfare, ethics and aesthetics (Marton and Booth, 1997, 178). Subsequently, in continental Europe pedagogy has evolved to include interrelationships between theories of learning, educational philosophy, curriculum and methods of teaching, mentoring and facilitating. By comparison, in the 
UK the term is infrequently and often erroneously used as shorthand for a method of teaching in schools. Unlike in the UK, pedagogy in continental Europe is also applied to a range of services that can typically include childcare and early years, youth work, parenting and family support services, secure units for young offenders, residential care and play work (Petrie et al, 2009). In further reorientations of pedagogy, social pedagogy and relational pedagogy have emerged notably in the province of youth work and social work as a means of more effectively addressing the integration of the intrapersonal, interpersonal and the communal, while actively promoting learner agency and shared experience. In the policy context outlined earlier, interest amongst policy makers in England in the possibilities of continental European pedagogy remains particularly remote while opportunities for education and staff development continue to be subject to intensive regulation and control. Meanwhile, pedagogy of the sort that has been advanced in continental Europe can offer significant possibilities for enhancing pupil well-being, while pedagogy in England is urgently in need of a significantly different orientation. Giroux (2004), in advancing the principles of Freire's critical pedagogy (1970), views pedagogy as a theoretical resource that is both determined and motivated by the problems that emerge in the 'in-between spaces/places/contexts that connect classrooms with the experiences of everyday life' (Giroux, 2004, 37). Echoing Van Manen's (1997) earlier reading of a post-modern pedagogy, we are encouraged not to think of pedagogy as process or content, medium or end but something that operates powerfully and constantly in the realm of the 'in-between'. It is in this realm of the in-between where the imperatives for a spiritual pedagogy may be both made vivid and promoted for pupil well-being; a pedagogy that necessarily involves, on the one-hand, resistance, courage and innovation in the 'in between' of school curricula and its regimes and, on the other a commitment to social justice, altruistic love and action. Hence, a pedagogy that may be worthy of the term 'spiritual' necessarily involves a commitment to the practice of human interaction as a fundamentally compassionate, dialogic and communal process. Pedagogy in this sense involves a strong ethical quality directed to the subjective felt experience and lives of others - as a simultaneous action involving intuitive and reflective powers combined with sensitivity and soulfulness.

In the domain of spiritual intrapersonal transcendence a renewed emphasis is then placed on the practice of care and its constituent empathic quality. In her substantial research of the field, Noddings advances an ethic of care where the greatest obligation of educators, inside and outside formal schooling, is to nurture the ethical ideals of those with whom they come in contact' (Noddings, 1984a, p. 49). In advancing an educational theory of care Noddings (1995, 190) advocates a four stage approach involving: modelling, dialogue, practice and confirmation. The first of these components requires a demonstrable moral commitment to the practice of care in every- 
day encounters in contrast to much of the contemporary and sanitised rhetorics that now surround a 'duty of care'. Dialogue for Noddings involves a 'common search for understanding, empathy, or appreciation' and 'builds up a substantial knowledge of one another that serves to guide our [caring] responses' (Noddings, 1992, 23). Thus, dialogue is more than a matter of effective communication but one in which ethical ideals are exchanged and through empathic encounters are engaged and mediated as a practice of professional empathy. In this third aspect of care Noddings calls for participatory experiences of care in which children are encouraged to participate in caring with adult models who show them how to care while confronting the difficulties and rewards of such work (Noddings, 1995, 191). In the final stage of her approach Nodding's advocates 'confirmation' in which the identification, affirmation and nurturing of a 'better self' is recognised 'as admirable, or at least acceptable, struggling to emerge in each person we encounter' (Noddings, 1995, 192).

Following Van Manen's (1997) conception of the pedagogical 'in-between' it is here that we might locate, position and begin the practice of a spiritual pedagogy of welfare that is first and foremost defined by the twin concepts of care and intrapersonal transcendence. The cornerstone of Noddings model of care is a commitment to empathic practice. While only limited consideration has been given to empathy as an attribute of human interaction and spirituality in education, healthcare, once again has a wide literature on the importance of empathy and its different manifestations. Gould $(1990,1172)$ describes empathy as an ability to appreciate the feelings of other people with whom we are not similar while Rogers $(1980,142)$ in his earlier account of the field considers this to be a sensitivity to changing, felt meanings and experiences which flow in the other person without recourse to judgement. Kunyk and Olson (2001) in their deconstruction of the concept suggest that there are five dominant conceptualizations, embracing: human trait; empathy as a professional state; empathy as a communication process; empathy as caring; and empathy as a special relationship (Kunyk and Olson, 2001, 318). Importantly, in these five conceptualisations Kunyk and Olson identify a repertoire of empathic approaches that are essential to good health care and the professional judgement that informs how these might be practiced. This, in turn, suggests a strong reciprocity between empathic orientations and care as intrapersonal transcendence of the spiritual kind.

Amongst the challenges that confront a reconceptualization of the spiritual as a pedagogy of pastoral welfare are assumptions that qualities of the spiritual and care are intrinsically 'soft' and emotive. While these are necessarily important qualities of a spiritual pedagogy, what Van Manen (1997: 21) calls 'action sensitive knowledge' offers an important response from the field of phenomenological research. Van Manen asserts that a rigorous human science is prepared to be 
'soft,' 'soulful,' 'subtle,' and 'sensitive' in its effort to bring the range of meanings of life's phenomena to our reflective awareness (Van Manen, 1997, 18). Combined with Hickson and Phelps (1997) observation that the spiritual person can be regarded as one who has a strong sense of social justice with a commitment to altruistic love and action there are further nuances with earlier Aristotelian origins of practice as action; involving a transition from the adherence to the regulation and codes of rule-directed behaviour known as techne to the sophistication of phronesis as wisdom in action (Carr and Kemmis, 1986). As Carr and Kemmis explain, techne is a disposition to 'act in a true and reasoned way according to the rules of the craft' (Carr and Kemmis,1986, 32). Craft of this sort, they assert, is coupled to the Greek idea of poietike, a form of instrumental 'means end' reasoning. In contrast to the craft-based regime of techne and poietike, educational practice proceeds not from an instrumental form of rule direction but through the informed action of praxis. According to Carr and Kemmis this involves reflection on the character and consequences of action; to reflexively change the knowledge base that informs it. While craft or technical knowledge is not reflexive, in that it does not change the conditions within which it operates, praxis, in contrast, remakes 'the conditions of informed action and constantly reviews action and the knowledge which informs it' (Carr and Kemmis, 1986, 33). The pinnacle of educational practice is then the Aristotelean principle of phronesis - a form of practical wisdom premised upon the disposition to act truly and rightly, involving 'prudent judgment which takes account of what would be morally appropriate and fitting in a particular situation' (Carr, 1987, 29). Claxton (2008), in his treatment of wisdom in teaching, also turns to Aristotelan traditions and similarly sees phronesis at the centre of wise professional action. In Claxton's view wise action involves three aspects. The first requires a moral quality in which wisdom 'takes account of the greater good and one's own higher, deeper, or more lasting values' (Claxton, 2008, 36). The second, he proposes, involves a level of disinterestedness that enables us to stand back from the mêlée in order to see the situation through a critical awareness of our cultural, emotional 'stock' and traits of personality. The third of Claxton's necessary attributes of wisdom, once again, involves empathy.

From the surveys of child well-being previously discussed, emotional, psychological and social wellbeing are common themes (NICE, 2013). Over the past twenty years much has been made, and variously misappropriated, of the work of Howard Gardner on Multiple Intelligence Theory (1983) and Daniel Goleman (1996) on Emotional Intelligence in meeting these perceived needs. In turn, their work has highlighted the development interpersonal relationships and the management of personal emotional states and behaviours for both young people and adults. In subtle contrast, the domain of spiritual intrapersonal transcendence configured with care and its constituent empathic quality offers a powerful but as yet largely underdeveloped addition to the teaching repertoire, 
enabling educators to meaningfully engage with the subjective experiences and interior lifeworlds of children and young people as a spiritual pedagogy of educational practice. Critically, this involves educators attending to an ethic of educational practice that pursues democratic dialogue of the sort advocated by Noddings to enable intrapersonal transcendence, care and modelling. By implication, this means teachers and educators working in school settings necessarily attending to the ethical qualities of care, both of others and of the self, as a means of realising phronesis in practice.

\section{Conclusion}

As the author has sought to demonstrate, the Pastoral welfare of children and young people in English schools faces a number of interrelated challenges that coalesce around increasingly intrusive neoliberal forms of performativity combined with growing public anxiety over the mental health and wellbeing of young people. In response, educators have been increasingly challenged in the conduct of meaningful educational work in schools.

While the spiritual realm can be both multifaceted and at times necessarily elusive, for it be purposefully configured as an educational practice in pastoral welfare in school settings also demands that it is understood in terms of an action of intrapersonal transcendence and care. It follows that this is not primarily a matter of curriculum content, prescribed or otherwise, but one of personal encounter and interaction in the liminal spaces of teacher-pupil interaction. A corollary of this is that a spiritual pedagogy necessarily involves professional attention to the development and refinement of educational practice as phronesis. Prudent judgement of the sort advanced in phronesis is neither a quick nor easy acquisition of desirable practice but a wisdom that is evolutionary and ethically guided through empathic orientation. In turn, this points to forms of personal professional self-renewal that while diffuse are essentially strongly emotionally, subjectively and ethically attuned. Hence, a spiritual pedagogy of the sort advanced in this paper closely aligns with a view of teaching as a theoretical resource that is both determined and motivated by the problems that emerge in the in-between contexts of teacher-pupil encounters and every-day life. Moreover, it follows that effective pastoral teaching resides in the province of all those charged with the education of children and young people, regardless of status, role, or curriculum affiliation. 


\section{$\underline{\text { References }}$}

Ball, S. (2003) 'The teacher's soul and the terrors of performativity', Journal of Education Policy, 18 (2): 215-228.

Benzein E., Norberg A. \& Saveman B. (1998) 'Hope: future imagined reality. The meaning of hope as described by a group of healthy Pentecostalists. Journal of Advanced Nursing 28, 1063-1070.

Best, R. (2008) 'In defence of the concept of 'spiritual education': a reply to Roger Marples', International Journal of Children's Spirituality, 13 (4) pp.321-329.

Best, R. (2000a) 'Concepts in Pastoral Care and PSE' in R. Best, P. Lang, C. Lodge and C.Watkins Pastoral Care and Personal Social Education: Entitlement and Provision, London: Continuum.

Best (2000b) (ed) Education for Spiritual, Moral, Social and Cultural Education, London: Continuum

Bigger, S. (2008) 'Secular spiritual education?' Educationalfutures, 1 (1). pp.60- 70.

Brown, A. (1996) Religious Education for All. London: David Fulton Publishers.

Burke , C. and Grosvenor, I. (2003) The School I'd Like: Children and Young People's Reflections on an Education for the 21st Century, London: RoutledgeFalmer.

Burnard P. (1988) 'Searching for meaning', Nursing Times 84, 34-36.

Campbell, J. and Husbands, C. (2000) On the reliability of OFSTED inspection in initial teacher training: A case study. British Educational Research Journal, 26 (1): 39-48.

Carr, W. and Kemmis, S. (1986). Becoming critical: Education, knowledge and action research. London: Falmer Press.

Carr, W. (1987). What is an educational practice? Journal of Philosophy of Education, 21 (2) pp. 2032.

ChildLine (2014) 'Can I tell you something? ChildLine Review 2012-13', http://www.nspcc.org.uk/globalassets/documents/research-reports/childline-review-2012-2013.pdf

ChildLine (2015) 'Under pressure ChildLine annual review 2013- 2014' http://www.nspcc.org.uk/globalassets/documents/annual-reports/childline-review-underpressure.pdf

The Children's Society, 'The Good Childhood Report 2015', https://www.childrenssociety.org.uk/.../TheGoodChildhoodReport2015.

Claxton, G. (2008).Wisdom: Advanced creativity? In A. Craft, H. Gardner and G. Claxton (2007) (Eds.) Creativity, wisdom, and trusteeship: Exploring the role of education, Thousand Oaks: Corwin Press. pp.35-48.

Coyle J. (2002) 'Spirituality and health: towards a framework for exploring the relationship between spirituality and health, Journal of Advanced Nursing, 37(6): 589-597. 
Cullingford, C. (1999) (ed.) An Inspector Calls: Ofsted and its effect on school standards, London: Kogan Page.

Ecclestone, K and Hayes, D. (2009) The Dangerous Rise of Therapeutic Education, Abingdon: Routledge.

Freire, P. (1970) Pedagogy of the Oppressed, London: Continuum.

Gardner, Howard (1983) Frames of Mind: The theory of multiple intelligences, New York: Basic Books.

Giroux, H. (2004) 'Critical Pedagogy and the Postmodern/Modern Divide: Towards a Pedagogy of Democratization' Teacher Education Quarterly, Winter 2004.

Goleman, D. (1996) Emotional Intelligence, London: Bloomsbury.

Gould, D. (1990) 'Empathy: a review of the literature with suggestions for an alternative research strategy' in Journal of Advanced Nursing, 15,11,1167-1174.

Halstead M.T. \& Mickley J.R. (1997) Attempting to unfathom the unfathomable: descriptive views of spirituality. Seminars in Oncology Nursing 13, 225-230.

Heron, J. (1998) Sacred Science: Person-centred Inquiry into the Spiritual and the Subtle, Ross-OnWye: PCCS Books.

Hickson J. \& Phelps A. (1997) 'Women's spirituality: a proposed model', Journal of Family Social Work 2, 43-57.

Hill, P.C. and Pargament, K.I. (2008) 'Advances in the Conceptualization and Measurement of Religion and Spirituality: Implications for Physical and Mental Health Research', Psychology of Religion and Spirituality, Vol S (1) pp. 3-17.

Hunt, C., and West, L. (2007) 'Towards an Understanding of What it Might Mean to Research Spiritually', Adult Education Research Conference. Paper 51. Kansas State University Libraries New Prairie Press (October 1, 2007). http://newprairiepress.org/aerc/2007/papers/51

Hutchings, M. (2015) 'Exam Factories: The impact of accountability measures on children and young people'. Research commissioned by the National Union of Teachers. NUT

https://www.teachers.org.uk/files/exam-factories.pdf

Jeffrey, B. and Troman, G. (2012) (eds.) Performativity in UK Education: Ethnographic Cases of its Effects, Agency and Reconstructions, Stroud: E\&E publishing.

Kunyk, D. and Olson, J.K. (2001) 'Clarification of Concepts of Empathy' in Journal of Advanced Nursing, 35, 3, 317-325.

Layard, R. and Dunn, J. (2009) A Good Childhood: Searching for values in a competitive age, London: Penguin. 
Lyotard, J-F. (1984) The Postmoderrn Condition: A Report on Knowledge, (G. Bennington and B.Massumi, Trans.) Manchester: Manchester University Press.

MacDonald, D.A. (2000) 'Spirituality: Description, Measurement, and Relation to the Five Factor Model of Personality', Journal of Personality 68 (1) pp. 153-197.

Marples, R. (2006) 'Against (the use of the term) 'spiritual education', Pastoral Care in Education, 11 (2) pp. 293-306.

Marton, F. and Booth, S. (1997) Learning and Awareness. Mahwah, N. J.: Lawrence Erlbaum.

Mayall, B. (2007) 'Children's Lives Outside School and their Educational Impact', (Primary Review Research Survey 8/1), Cambridge: University of Cambridge Faculty of Education.

NICE (2013) 'Social and Emotional Wellbeing for Children and Young People'. September 2013 https://www.nice.org.uk/advice/lgb12/chapter/introduction.

Noddings, N. (1984a) Caring: a feminine approach to ethics and moral education, Berkeley, CA: University of California Press.

Noddings, N. (1995) Philosophy of Education, Boulder, CO: Westview Press,

Noddings, N. (1992) The Challenge to Care in Schools: An alternative approach to education. New York: Teachers College Press.

OECD (2015) How's Life? 2015: Measuring Well-being, OECD Publishing, Paris.

DOI: http://dx.doi.org/10.1787/how life-2015-en

Office for National Statistics (2014) 'Measuring National Well-being: Children's Well-being, 2014'. 06 March 2014. http://www.ons.gov.uk/ons/dcp171776 355140.pdf

Park, J. (2013) 'Detoxifying School Accountability', London: DEMOS. 3-14.

Petrie, P., Boddy, J., Cameron, C. Heptinstall, E., McQuail, S., Simon, A. and Wigfall , V. (2009) Pedagogy - a holistic, personal approach to work with children and young people, acrossServices: European models for practice, training, education and qualification. Thomas Coram Research Unit, Institute of Education, University of London BRIEFING PAPER - Update 2009.

Pollard, E.L. and Lee P.D. (2003) 'Child Well-being: A Systematic Review of the Literature', Social Indicators Research, 61 (1) pp. 59-78.

Simon, B. (1981) 'Why No Pedagogy in England?' in B. Simon and W. Taylor (eds.) Education in the Eighties: the central issues, pp,121-145, London: Batsford.

Sulmasy, D. (1999) ‘Is Medicine a Spiritual Practice?’ Academic Medicine, 74 (9) pp.1002-1005.

UNICEF (2007) An overview of child well-being in rich countries, UNICEF Innocenti Research Centre, Report Card 7.

Van Manen, M. (1997) Researching Lived Experience: Human Science for an Action Sensitive Pedagogy, 2nd edition. London, Ontario: Althouse Press. 
Wayne Ross E. and Gibson, R. (2006) (ed.) Neoliberalism and Educational Reform, Cresskill NJ: Hampton Press.

World Health Organisation (2012) 'Social determinants of health and well-being among young people: health behaviour in school-aged children study: international report from the 2009/2010 survey', http://www.euro.who.int/__data/assets/pdf_file/0003/163857/Social-determinants-ofhealth-and-well-being-among-young-people.pdf. 